\title{
Carlos Ribeiro (1813-1882), a segunda parte da "Descripção do solo quaternário das bacias hydrographicas dos rios Tejo e Sado", o "Homem terciário" e os concheiros mesolíticos do vale do Tejo
}

\section{Carlos Ribeiro (1813-1882), the second part of the "Descripção do solo quaternário das bacias hydrographicas dos rios Tejo e Sado", the "Tertiary man" and the Mesolithic shellmiddens of the Tagus valley}

João Luís Cardoso ${ }^{1}$

Recibido 08/07/2014

Aceptado 30/09/2015

\section{Resumo}

Apresenta-se estudo de manuscrito inédito da autoria de Carlos Ribeiro, pioneiro da Geologia e da Pré-História portuguesas. O manuscrito, iniciado em 1867, jamais foi publicado, pelas razões que agora se apontam, e constituía a segunda parte de uma obra dedicada ao estudo das formações quaternárias de Portugal, cuja primeira parte, relativa às bacias sedimentares do Tejo e do Sado, foi publicada em 1866.

No manuscrito caracteriza-se a estratigrafia dos depósitos então considerados como quaternários, articulando-se tais observações com a existência de indústrias líticas (os célebres eólitos terciários), desde as camadas mais antigas do chamado Grupo Inferior, até aos depósitos de conchas de origem antrópica existentes na parte mais alta da sequência, o Grupo Superior (os célebres concheiros mesolíticos do vale do Tejo).

Deste modo, o estudo ora apresentado constitui importante contributo para o conhecimento da realidade científica que presidiu a uma das primeiras investigações sobre a Geologia do Quaternário e a Pré-História na Península Ibérica.

Palavras-Chave: Carlos Ribeiro; Geologia do Quaternário; Eólitos; Concheiros mesolíticos; vale do Tejo.

\begin{abstract}
We present the study of a manuscript from Carlos Ribeiro, pioneer of the Portuguese Geology and Prehistory. This document, initiated in 1867 was never achieved by the reasons explained, and constituted the second part of the study dedicated to the quaternary formations of the Portuguese territory, whose first part was published in 1866.

In the manuscript, the stratigraphy of the deposits then attributed to the Quaternary, as well as their archaeological contents are discussed, since the oldest layers of the so-called "Grupo Inferior" (the famous tertiary eoliths), until the most modern deposits, the so-called "Grupo Superior" represented, amongst others, by the famous mesolithic shellmiddens of the Tagus valley. In this order, this study constitutes an interesting contribution to the knowledge of the scientific conditions that characterized one the first researches concerned the Quaternary geology and Prehistory in the Iberian peninsula.
\end{abstract}

Keywords: Carlos Ribeiro; Quaternary Geology; Eoliths; Mesolithic Shelmiddens; Tagus valley.

1 Academia das Ciências de Lisboa. Catedrático de Arqueologia e Pré-História da Universidade Aberta (Lisboa). Centro de Estudos Arqueológicos do Concelho de
Oeiras (Câmara Municipal de Oeiras). cardoso18@netvisao.pt 


\section{INTRODUÇÃo}

Em 1866 Carlos Ribeiro publicou monografia dedicada à caracterização dos depósitos quaternários das bacias sedimentares do Tejo e do Sado, acompanhada de uma carta geológica com a delimitação de tais terrenos, e de cortes geológicos que abarcaram toda a largura do território nacional, os quais, por quase 120 anos, constituíram os únicos no seu género realizados em Portugal (Ribeiro, 1866) (Fig. 1).

Tal memória, onde apenas se caracterizam os depósitos quaternários mais antigos, correspondentes ao Grupo Inferior, deveria ser seguida pela publicação de outra, aliás explicitamente prevista, já que a própria capa da brochura da única parte publicada refere que se

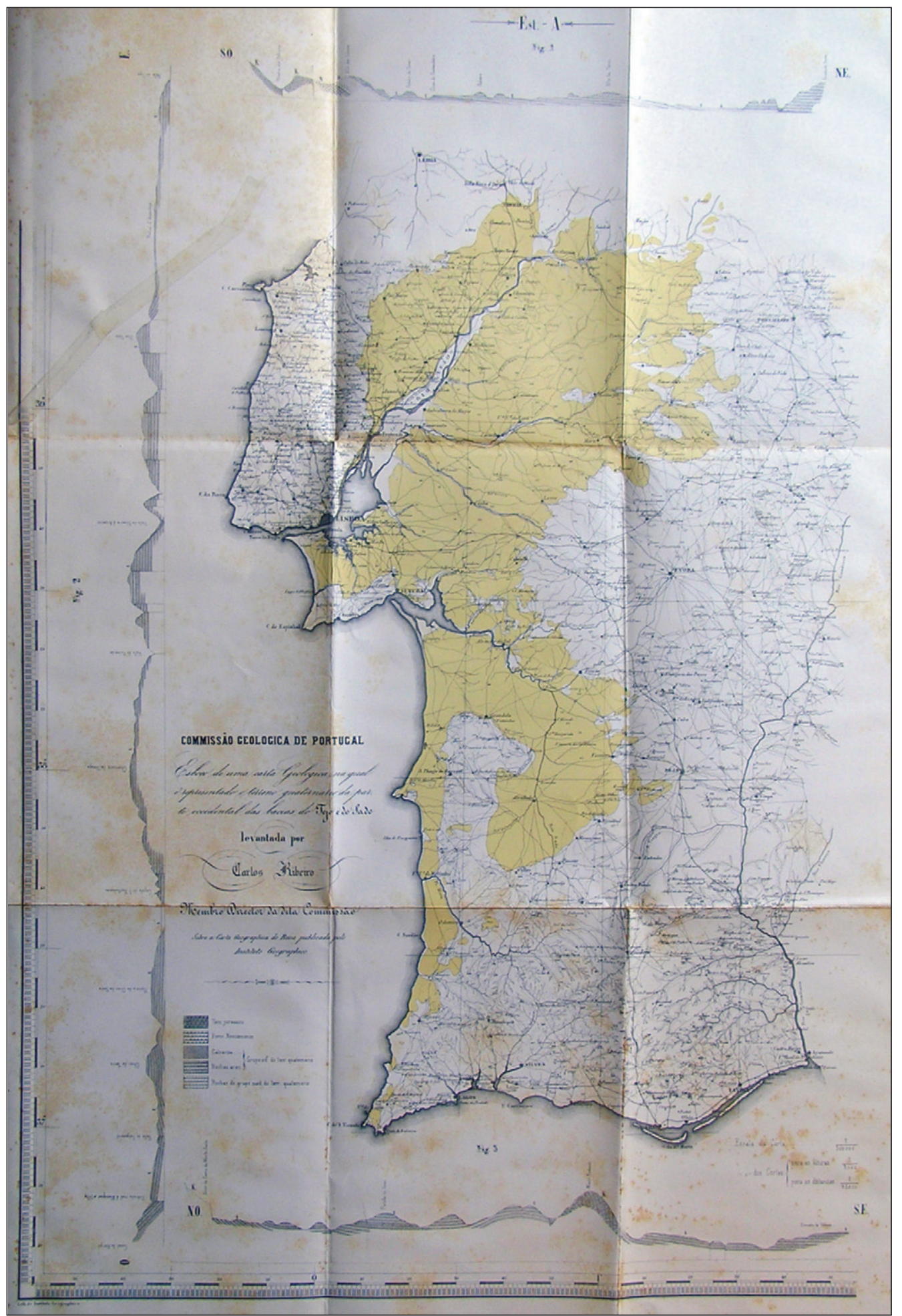

Fig. 1. Carta geológica dos terrenos quaternários das bacias do Tejo e do Sado à escala de 1/500 000 (Ribeiro, 1866, Est. A). 
trata do $1 .^{\circ}$ Caderno, o que pressupõe a impressão ulterior de pelo menos outro. Com efeito, o sumário da obra apresenta já aspectos respeitantes aos Grupos Médio e Superior, a par do alargamento geográfico das observações, pelo que, aquando da publicação do primeiro caderno, a futura obra já se encontrava claramente delineada no espírito do Autor.

O manuscrito ora estudado, foi objecto de transcrição integral, já publicada (Cardoso, 2013 a). Nele, a caracterização dos depósitos quaternários, que no trabalho publicado em 1866 se limitava à região a sul do Tejo, é agora alargado a todo o País, sendo acompanhado de um mapa à escala de $1 / 20000000$ (Fig. 2), registando afloramentos desde Trás-os-Montes ao Algarve, o qual se manteve inédito, tal como o manuscrito, onde se caracterizam os depósitos até então conhecidos repartidos pelos três grupos estratigráficos considerados. Trata-se, pois de um assinalável avanço face à obra publicada em 1866, decorrente de um notá-

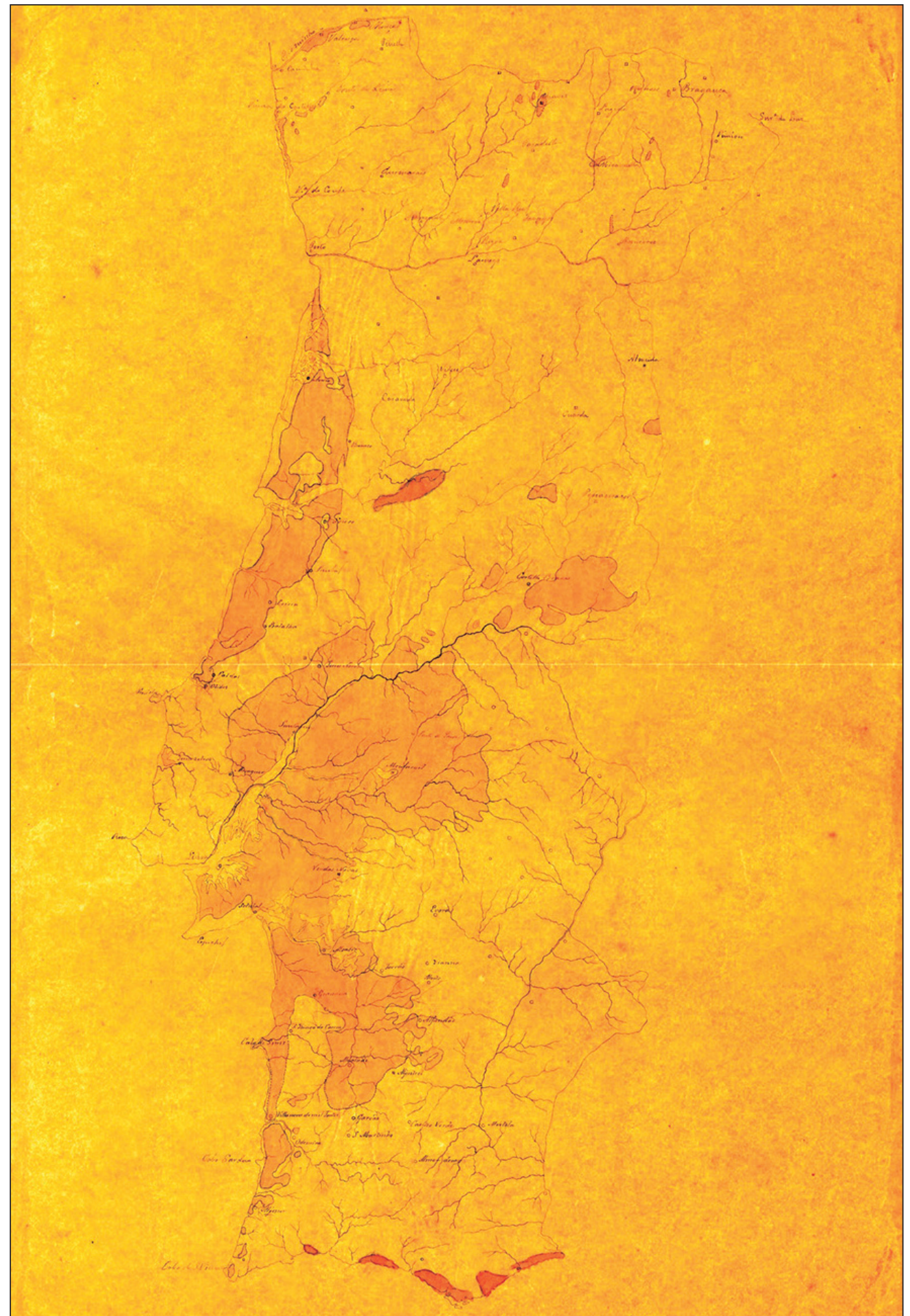

Fig. 2. Carta geológica dos terrenos quaternários de Portugal. Original que acompanha o manuscrito estudado. 
vel trabalho de campo, de registo e descrição dos depósitos, em resultado de observações efectuadas sempre in loco.

Por outro lado, a redacção do manuscrito teve origem próxima no convite endereçado por De Verneuil, Presidente da Sociedade Geológica de França, a 23 de Maio de 1867, para que Carlos Ribeiro, na sequência da publicação da primeira parte da sua memória sobre os depósitos quaternários portugueses, apresentasse àquela Sociedade síntese sobre o referido tema.

Este respondeu-lhe afirmativamente, tendo aquela comunicação sido apresentada na sessão de 17 de Junho de 1867 , e ulteriormente publicada no respectivo Boletim (Ribeiro, 1867) (Fig. 3).

Carlos Ribeiro recebeu, pouco depois, a 16 de Julho do mesmo ano, ou seja, menos de um mês após a leitura pública do seu trabalho em Paris, uma nova carta de De Verneuil, onde este apresenta diversas dúvidas sobre as conclusões então produzidas (Ribeiro, 1871: 53 , nota 1):

« Je suis toujours un peu étonné de l’épaisseur de votre terrain quaternaire et des circonstances suivantes que vous mentionnez:

1. Le quaternaire a 400 mètres;

2. Il est soulevé et quelquefois en stratification inclinée jusqu'à la verticale;

3. Il contient des masses de calcaire dur semblable à du calcaire secondaire;

4. ${ }^{\circ}$ Enfin, et ce qu'il y a de plus curieux, on y trouve des haches fabriqués de main de l'homme en silex et en quartzite, et $c^{\prime}$ est à la base du terrain que l'on trouve ces instruments, c'est-à-dire que depuis leur confection il s'est formé un dépôt de 400 mètres d'épaisseur $»$.
Estas observações exigiam cuidadosa reflexão, que Carlos Ribeiro não tinha anteriormente dispensado à redacção da comunicação, aliás extensa, pois abarca 20 páginas do Boletim. Com efeito, como ele próprio declara, o convite apanhou-o desprevenido, pois encontravase de partida para trabalho de campo nas Beiras e, porque não queria deixar de responder positivamente ao mesmo, viu-se privado, no decurso da redacção, de apon-
EXTRAIT DU BULLETIN DE LA SOCIÉTE GÉOLOGIQUE DE FRANCE, $2^{\mathrm{e}}$ série, t. XXIV, p. 692 , séance du 17 juin 1867.
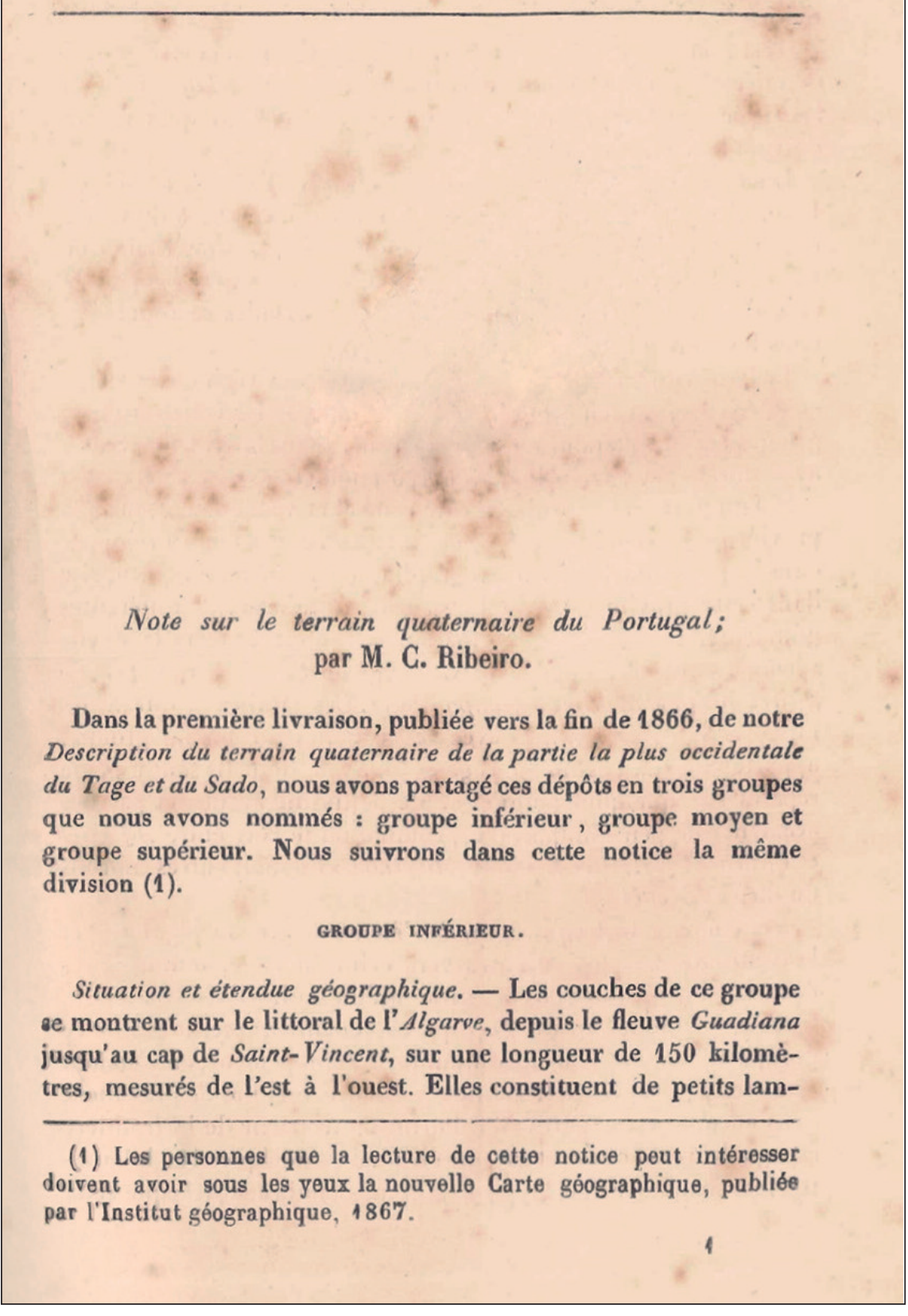

Fig. 3. Primeira página do artigo resultante da comunicação apresentada por Carlos Ribeiro à Sociedade Geológica de França, a 17 de Junho de 1867 (Ribeiro, 1867). 
tamentos, de tempo e de sossego, do que resultou obra imperfeita, como é referido pelo próprio:

"Quando recolhemos do campo e lemos com algum vagar a minuta daquele trabalho conhecemos quanto precisava de ser revisto e corrigido antes de ser entregue á estampa. É por isso que nos resolvemos redigir sobre aquella nota a presente memoria juntando-lhe uma pequena carta com o esboço geológico do terreno quaternário de Portugal e oferece-la à nossa Academia Real das Sciencias de Lisboa" (2. ${ }^{\circ}$ caderno).

Está, pois, explicada as razões que determinaram concretamente a redacção do manuscrito agora estudado.

\section{Características do documento}

O manuscrito é constituído por quatro versões subordinadas ao título "Breve noticia acerca do terreno quaternário de Portugal", escritas em cadernos de características distintas, a maioria com as dimensões de 31 por $21 \mathrm{~cm}$, embora também tenham sido utilizadas folhas lisas de papel de menores dimensões.

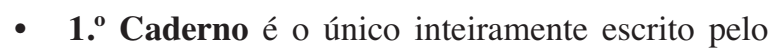
punho de Carlos Ribeiro (Fig. 4). Apresenta a caracterização completa dos três grupos de depósitos, ordenados do mais antigo para o mais moderno: Grupo Inferior, Grupo Médio e Grupo

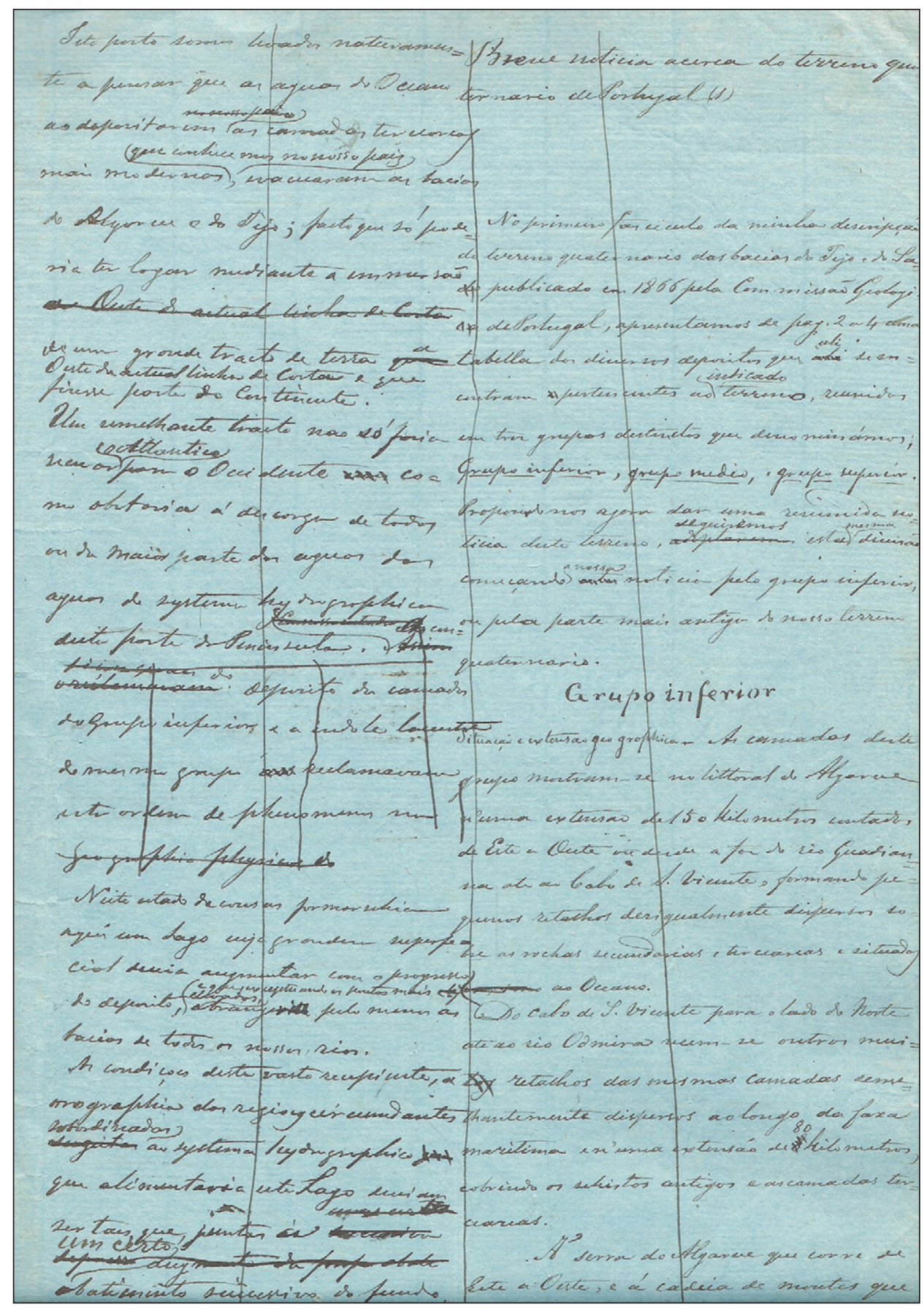

Fig. 4. Primeira página da versão mais antiga (Caderno n. ${ }^{\circ}$ 1) do manuscrito estudado, escrita por Carlos Ribeiro. 
Superior. Este Caderno integra ainda uma versão mais moderna do Grupo Inferior, passada a limpo por copiador (por certo funcionário administrativo da Comissão Geológica de Portugal), com correcções autógrafas de Carlos Ribeiro.

- 2. ${ }^{\circ}$ Caderno, escrito por copiador, inclui igualmente a caracterização dos três grupos de depósitos, sendo aquele onde as correcções autógrafas de Carlos Ribeiro são mais extensas, recorrendo frequentemente a tiras de papel coladas (Fig. 5), ou mesmo aproveitando o verso de uma carta que lhe foi remetida para Mirandela, datada de 13 de Setembro de 1867, importante para estabelecer uma data post quem para a redacção do manuscrito.

- 3. ${ }^{\circ}$ Caderno é em parte escrito pelo copiador do Caderno n. ${ }^{\circ}$ 2, possuindo também correcções autógrafas de Carlos Ribeiro, que escreveu pelo seu punho a última parte do texto relativo ao Grupo Inferior, faltando os textos dos Grupos Médio e Superior.

- $\quad$ 4. $^{\circ}$ e último caderno é escrito por outro copiador dos dois cadernos anteriores, sem correcções de Carlos Ribeiro e interessando apenas o Grupo Inferior.

Conclui-se que no processo de construção do texto final, intervieram pelo menos três copiadores, que foram passando a limpo as sucessivas minutas revistas por Carlos Ribeiro. Mas foi apenas a parte da memória relativa ao Grupo Inferior - a qual, numa versão mais extensa, tinha sido já publicada, em 1866 - a única que se pode considerar concluída.

O manuscrito apresenta-se, pois, longe de terminado, apesar de se conhecer a sua extensão total, com base nas duas versões mais antigas, as únicas que se apresentam completas. É inegável o árduo e exigente trabalho envolvido na sua preparação, que por certo terá exigido muito tempo e esforço a Carlos Ribeiro.

\section{Aspectos Científicos de CARÁCTER GERAL E A IMPORTÂNCIA DA INFORMAÇÃO ARQUEOLÓGICA}

Importa evidenciar diversos aspectos patentes no manuscrito:

1 - O conhecimento de terreno do Autor, revelado pela descrição pormenorizada dos afloramentos, sequências estratigráficas, características litológicas e mineralógicas dos depósitos, desde Trásos-Montes ao Algarve. Tais registos só podiam ter sido obtidos no decurso de prolongados reconhecimentos geológicos de campo, iniciados pelo próprio em 1863, de que resultaram a carta geológica que acompanha o manuscrito. Note-se que a primeira edição da Carta Geológica de
Portugal à escala de 1/500 000 data de 1876 e é da autoria de Carlos Ribeiro e de Nery Delgado, pelo a carta ora publicada é o mais antigo documento cartográfico de natureza geológica que abarca a totalidade do território continental.

2 - A importância conferida às observações de De Verneuil sobre a idade quaternária dos depósitos estudados, é atestada pela desenvolvida resposta, estruturada em dez pontos, que evidenciam um pensamento científico claro e organizado.

3 - A alusão frequente à ocorrência de materiais talhados pelo Homem pré-histórico, o que justificava, no quadro conceptual da época, a atribuição ao Quaternário dos depósitos correspondentes, não deixando Carlos Ribeiro de se surpreender com tal conclusão: "É realmente admirável extrahir um sílex ou um quartzite do seio d’uma camada que tem por cima, assentadas de outras camadas com 50, 100 e 200 metros de espessura em cujas peças se reconhece que antes de ali se sepultarem já tinham passado pela mão do homem!" (2. ${ }^{\circ}$ Caderno).

4 - A atenção dada à evolução do território nos últimos tempos geológicos, com a valorização dos concheiros mesolíticos das ribeiras de Magos e de Muge, alguns deles por ele identificados em 13, 14 e 24 de Abril de 1863 (Cardoso e Rolão, 2001/2002; Cardoso, 2013, 2015), num dos quais (o concheiro do Cabeço da Arruda), Carlos Ribeiro tinha já realizado escavações em 1864 (Costa, 1865). Da sua implantação no terreno e com base nas espécies de moluscos identificadas, Carlos Ribeiro concluiu, e bem, que a sua formação antecedeu imediatamente a última colmatação sedimentar do vale do Tejo, onde, nas camadas subjacentes às férteis terras da lezíria, veio a encontrar, em sondagens por si mandadas realizar, grandes concentrações das mesmas espécies de moluscos que constituem aqueles amontoados artificiais: "Todos estes factos dizem-nos que as aguas do Oceano avassalavam todo o valle do Tejo até Santarém pelo menos na epocha em que viveram os homens do Cabeço d'Arruda e por conseguinte em tempo que o nosso paiz, estava ainda alguns metros mais baixo do que hoje se vê (...)" (2. Caderno). A valorização dos movimentos tectónicos ascensionais foi, assim, preferida, à explicação eustática, da subida do nível do mar, que é aquela que, na verdade, justifica a última fase do assoreamento do vale do Tejo. Idêntica explicação é dada para os cordões lumachélicos que se desenvolvem a diversas altitudes ao longo do litoral meridional da serra da Arrábida, que foi o primeiro a reconhecer. 


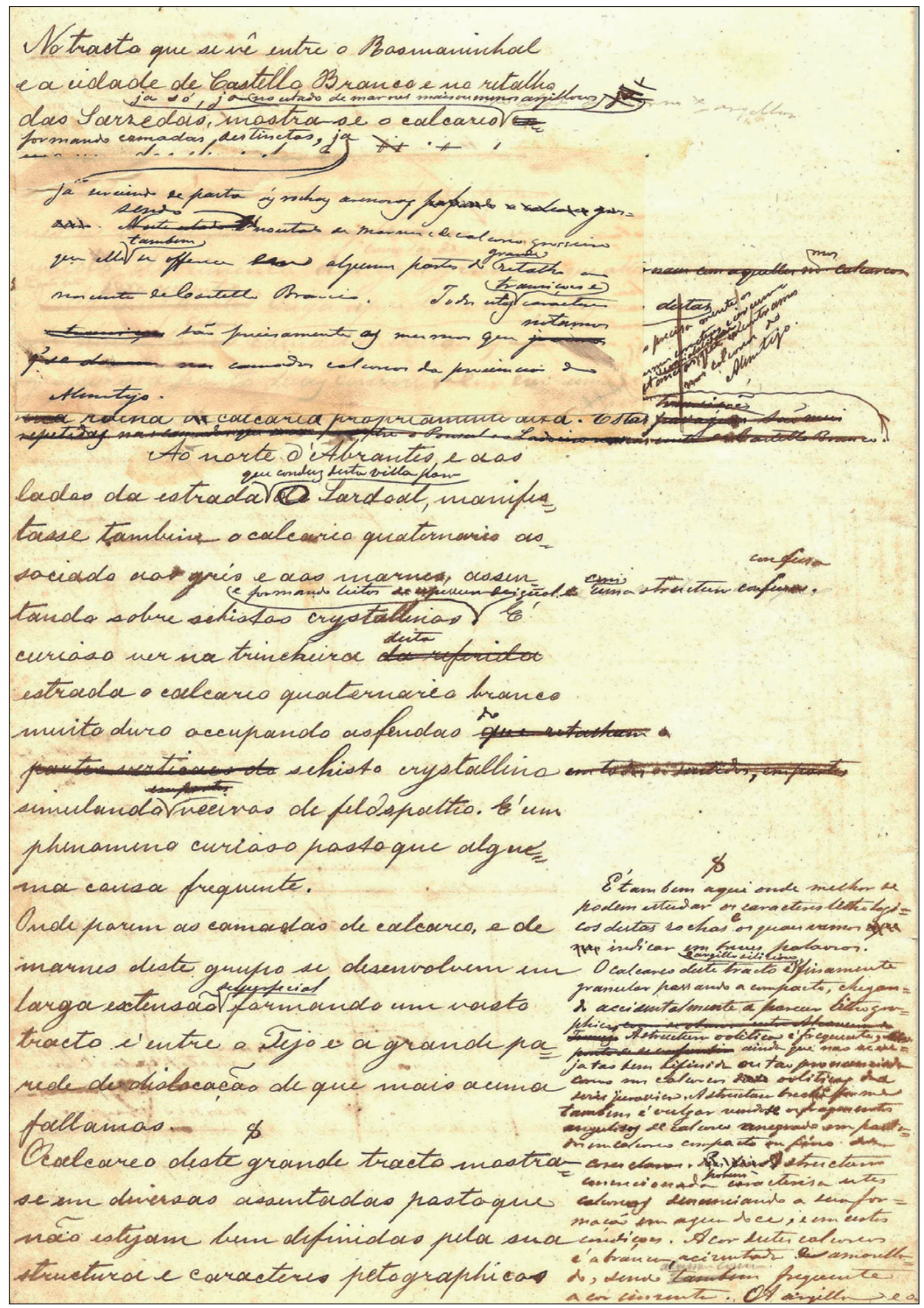

Fig. 5. Página da segunda versão do manuscrito estudado, com letra do copiador e correcções autógrafas de Carlos Ribeiro. 


\section{Por Que razão este manuscrito não SE CONCLUIU?}

Tratando-se de manuscrito claramente inacabado, importa averiguar as razões do desinteresse de Carlos Ribeiro pela sua conclusão.

Sabe-se que a redacção desta obra deve ter avançado muito na segunda metade do ano de 1867 , já que se impunha dar rápida resposta às observações de De Verneuil. Para tal conclusão concorre também a carta utilizada no $2{ }^{\circ}$ Caderno como rascunho, datada de 13 de Setembro de 1867, bem como a alusão à monografia de Nery Delgado dedicada à Gruta da Casa da Moura, então ainda no prelo da Imprensa da Academia Real das Ciências, datada igualmente de 1867 (Delgado, 1867). Deste modo, pode concluir-se que o trabalho, em configuração próxima da actual, se encontrava concluído nos finais de 1867. Em 1868, o trabalho pouco ou nada terá avançado. Com efeito, as perturbações que sobrevieram na Comissão Geológica de Portugal, e que conduziram à sua consequente extinção, a 1 de Fevereiro de 1868 , levaram a que os então Major de Artilharia Carlos Ribeiro e o Tenente de Engenharia Nery Delgado fossem incumbidos, pelo director do Instituto Geográfico, General Filipe Folque, da redacção de relatório sobre a arborização geral do país, recorrendo para tanto às observações anteriormente registadas por todo o país, em resultado das suas prolongadas missões no terreno, tendo efectivamente tal relatório saído dos prelos da Tipografia da Academia Real das Ciências nesse mesmo ano de 1868 (Ribeiro e Delgado, 1868).

Sabe-se que Carlos Ribeiro introduziu melhorias no manuscrito em 1869 , pois uma nota infrapaginal contida no $4 .^{\circ}$ Caderno, o mais moderno de todos, alude à impossibilidade do próprio consultar documentação por si recolhida em virtude da aplicação do Decreto de 23 de Dezembro de 1868 , que determinou a transferência para a Escola Politécnica, da livraria, colecções e outra documentação da já então extinta Comissão Geológica. Deste modo, importa encontrar os motivos que estiveram na origem da não conclusão do trabalho após a reconstituição, em Dezembro de 1869, daquela Comissão, embora com outro nome - Secção dos Trabalhos Geológicos de Portugal - e com Carlos Ribeiro à frente da mesma.

O que se pode concluir é que nessa altura se verificou mudança de opinião de Carlos Ribeiro sobre a idade das camadas dos seus Grupos Inferior e Médio, que já não seriam quaternárias, como julgava até então, mas sim terciárias. Para tal foram decisivas as informações chegadas de além-fronteiras. Em França, discutia-se abertamente, então, a hipótese da existência de uma Humanidade pré-quaternária. Assim, o Abade Bourgeois, publicou em 1867 os sílices terciários recolhidos na base dos calcários de Beauce, trabalho citado por Carlos Ribeiro, no seu estudo de 1871 (Fig. 6), no qual declara, em defesa de uma humanidade terciária:

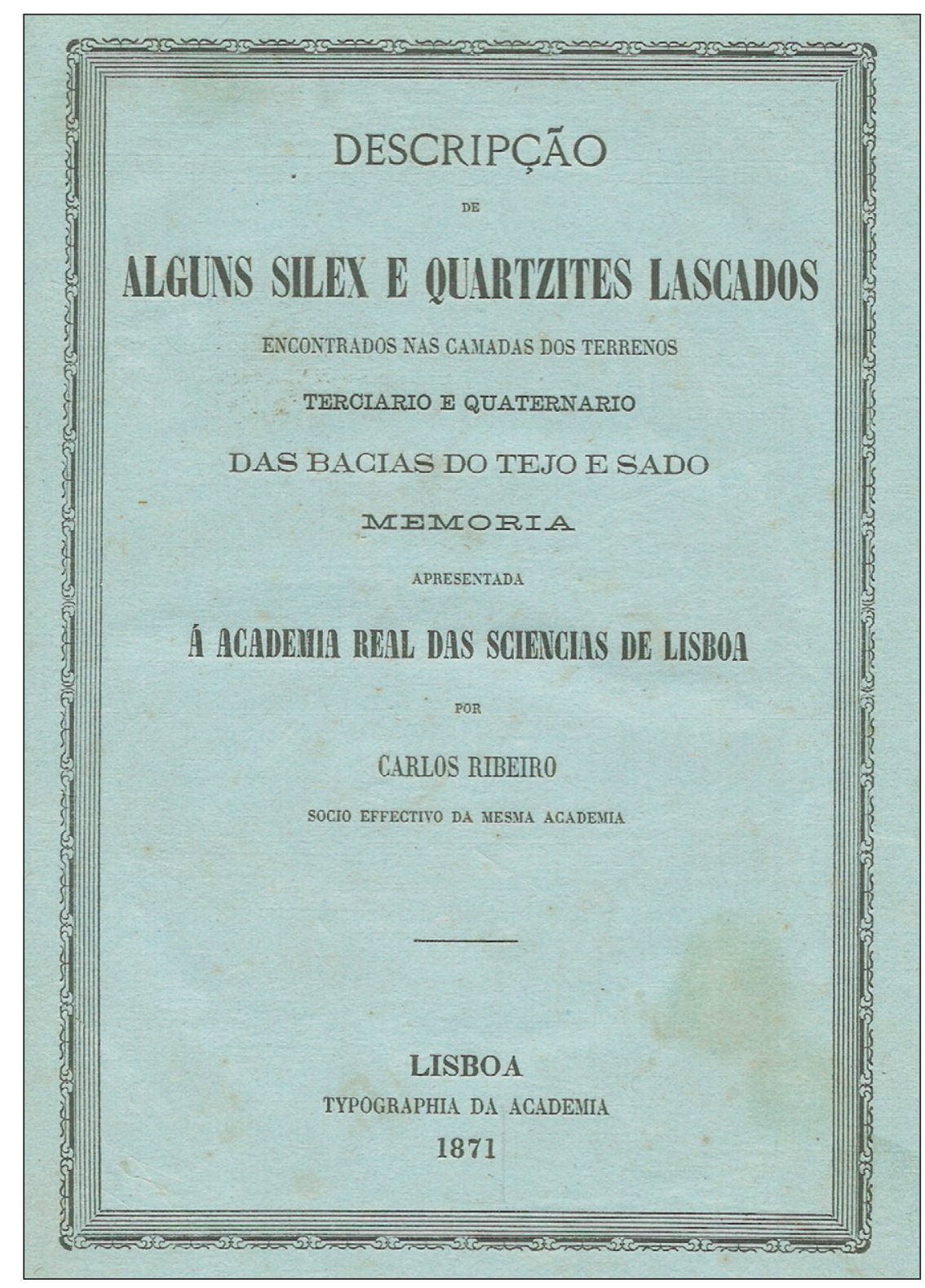

Fig. 6. Capa da brochura da memória apresentada por Carlos Ribeiro à Academia Real das Ciências de Lisboa em 1871 (Ribeiro, 1871). 
"Hoje acabaram para nós todas as hesitações e dúvidas, que se tinham levantado no nosso espírito, nascidas unicamente da idéa preconcebida - que a espécie humana não tinha precedido na serie dos tempos geológicos o período diluvial ou quaternário -; e assim devia acontecer, depois dos estudos que ultimamente fizemos" (Ribeiro, 1871: 53).

Percebe-se bem o alívio de Carlos Ribeiro nesta declaração, que assim lhe permitia resolver um problema científico, para o qual não conseguira reunir explicações convincentes às observações apresentadas por De Verneuil, ou seja, a ocorrência de depósitos quaternários com mais de $400 \mathrm{~m}$ de potência, com base no critério da presença de indústrias líticas (os eólitos), que, na verdade, não possuíam, como depois se verificou quaisquer traços de trabalho humano. Trata-se de um interessante exemplo de como um erro científico, pode, na verdade, contribuir para o avanço dos conhecimentos, pois no caso em apreço, foi a incorrecta admissão de uma humanidade terciária, por via da atribuição de intencionalidade aos "eólitos", que esteve na origem da correcta integração estratigráfica dos depósitos do Grupo Inferior no Miocénico, pelo próprio Carlos Ribeiro, logo em 1871 (Ribeiro, 1871). Apenas os depósitos do Grupo Superior mantiveram neste último trabalho a sua integração no Quaternário, pertencendo os do Grupo Médio ao Mio/Pliocénico.

$\mathrm{Na}$ época, o novo paradigma, imediatamente abraçado por Carlos Ribeiro, foi a certidão de óbito do manuscrito que, tão empenhada e proficientemente preparara nos anos anteriores, no afã de demonstrar a idade quaternária dos depósitos dos Grupos Inferior, Médio e Superior; assim, do manuscrito, apenas se aproveitaram as principais observações estratigráficas, as quais, depois de revistas à luz do novo critério cronoestratigráfico, foram incorporadas no seu estudo de 1871 .

Esta mudança de paradigma teve, na época, outras consequências. É o caso da não distribuição de duas folhas da Carta Geológica de Portugal à escala de 1/100 000, impressas em 1866 e 1867, por atribuírem ao Quaternário formações doravante consideradas - e bem - como terciárias, apesar dos altos custos da impressão cromolitográfica, as quais foram dadas a conhecer apenas em 1941 por outro ilustre geólogo e arqueólogo, o Doutor Georges Zbyszewski (Zbyszewski, 1949), que com propriedade se pode considerar o continuador da obra de Carlos Ribeiro, até por ter sido, conjuntamente com Henri Breuil a esclarecer, em 1942, o mistério dos eólitos da Ota, recolhidos por Carlos Ribeiro mais de sessenta anos antes (Breuil e Zbyszewski, 1942; Cardoso, 1999/2000).

\section{REFERÊNCIAS}

Breuil, H. e Zbyszewski, G. (1942): Contribution à l'étude des industries paléolithiques du Portugal et de leurs rapports avec la géologie $d u$ Quaternaire. 1 - Les principaux gisements des deux rives de l'ancien estuaire du Tage. Serviços Geológicos de Portugal. Lisboa (Comunicações dos Serviços Geológicos de Portugal, 26).

Cardoso, J.L. (1999/2000): “As investigações de Carlos Ribeiro e de Nery Delgado sobre o "Homem Terciário": resultados e consequências na época e para além dela". Estudos Arqueológicos de Oeiras, 8: 33-54.

Cardoso, J.L. (2013a): "Carlos Ribeiro, a "Breve noticia acerca do terreno quaternario de Portugal" e a questão do Homem Terciário em Portugal. Estudos Arqueológicos de Oeiras, 20: 27-88.

Cardoso, J.L. (2013b): “Carlos Ribeiro e o reconhecimento do solo quaternario do vale do Tejo: enquadramento geológico dos concheiros mesolíticos das ribeiras de Magos e de Muge. Estudos Arqueológicos de Oeiras, 20: 89-100.

Cardoso, J. L. (2015): “Carlos Ribeiro and Francisco António Pereira da Costa: dawn of the Mesolithic shellmiddens of Muge (Salvaterra de Magos)", em N. Bicho, C. Detry, T. D. Price. e E. Cunha (eds.): Muge 150th: The 150th Anniversary of the Discovery of Mesolithic Shellmiddens. Cambridge Scholars Publishing, em publicação.

Cardoso, J.L. e Rolão, J.M. (1999/2000): "Prospecções e escavações nos concheiros mesolíticos de Muge e de Magos (Salvaterra de Magos): contribuição para a história dos trabalhos arqueológico efectuados". Estudos Arqueológicos de Oeiras, 8: 83-240.

Costa, F. A. P. (1865): Da existencia do Homem em epochas remotas no valle do Tejo. Primeiro opusculo. Noticia sobre os esqueletos humanos descobertos no Cabeço da Arruda. Imprensa Nacional. Lisboa.

Ribeiro, C. (1866): Estudos geologicos. Descripção do solo quaternario das bacias hydrographicas do Tejo e Sado. 1. ${ }^{\circ}$ Caderno. Typographia da Academia Real das Sciencias. Lisboa.

Ribeiro, C. (1867): "Note sur le terrain quaternaire du Portugal". Bulletin de la Société Géologique de France, Série 2, 24: 692-717.

Ribeiro, C. (1871): Descripção de alguns sílex e quartzites lascados encontrados nas camadas dos terrenos terciário e quaternário das bacias do Tejo e Sado. Memoria apresentada à 
Academia Real das Sciencias de Lisboa. Typographia da Academia. Lisboa.

Ribeiro, C. e Delgado, J.F.N. (1868): Relatorio acerca da arborização geral do Paiz. Typographia da Academia Real das Sciencias. Lisboa.

Zbyszewski, G. (1949): Notice sur deux cartes géologiques inédites, œuvres de Carlos Ribeiro et J. F. Nery Delgado. Serviços Geológicos de Portugal. Lisboa. 